\section{Mcdonaldização no jornalismo, espetacularização da notícia}

Thaís de Mendonça Jorge

\section{Resumo}

O conceito de mcdonaldização, proposto neste trabalho, se baseia nos princípios da homogeneidade e da velocidade aplicados ao processo jornalístico, notadamente o jornalismo digital. Isso resulta em textos estandardizados, pasteurizados, superficiais, sem aprofundamento, culminando naquilo que denominamos jornalismo binário. O jornalismo binário seria o jornalismo reduzido à sua mínima essência, sem o cuidado de "ouvir o outro lado" ou de conferir as fontes. Temos, assim, duas hipóteses: 1) a mcdonaldização é um fenômeno que incide sobre o jornalismo e afeta as notícias; e 2) o jornalismo binário é conseqüência, levando a um produto de menor qualidade. Paralelamente, tecemos o argumento de que a espetacularização seria um recurso que encontra no jornalismo digital (mcdonaldizado) as condições para sua inserção no mundo das notícias.

\section{Palauras-chave:}

Mcdonaldização, Jornalismo digital, Jornalismo on-line, Produção da notícia, Espetáculo

\title{
Medonaldization in journalism, the spectacularization of the news
}

\section{Abstract}

The mcdonaldization concept is based on the homogeneity and velocity principles applied into a journalistic process, mainly the digital one. Its results are a kind of standardized, 'pasteurized', superficial texts, without depth; what we call 'binary journalism'. 'Binary journalism' is the journalism reduced to its minimum essence, that is, a journalism made without listening to "the other side" and without checking. We have two hypotheses: 1 ) the mcdonaldization is a phenomenon that affects the journalism and the news themselves; and 2) binary journalism as a consequence leads to lesser quality products. Besides, we also argue that spectacularization is a resource that meets the conditions to be inserted in the news' field, in digital ('mcdonaldized') journalism.

Key words:

Mcdonaldization, Digital journalism, On-line journalism, News production, Spectacle 
O mundo produziu, nas três últimas décadas, mais informações do que nos 5 mil anos anteriores. Em uma edição de domingo de The New York Times, o leitor encontra cerca de dois milhões de linhas, com 12 milhões de palavras e 5,5 quilos de papel. Na era da informática, essas informações se multiplicam pelo mundo num emaranhado de redes de fibra ótica, interligadas a satélites. Sob o signo da ultravelocidade, dissolvem-se as fronteiras geográficas, formando um continuum de dados sem correspondências cronológicas. A noção de tempo e espaço é transfigurada. Tudo é veloz e imediato. O tempo real se dilui e se restaura sem direito a intervalos, no espaço ilimitado da internet.

Em mais de uma década de jornalismo digital no Brasil, os portais noticiosos reinventaram paradigmas de notícias. Sites agregam novos serviços, não necessariamente jornalísticos, criam-se novos padrões de notícias que às vezes se chocam com os princípios básicos da profissão. As empresas investem em tecnologia, não para o aprimoramento da informação, mas para chegar ao consumidor antes do concorrente e dar informação em quantidade. Essa aparente contradição é o que Sylvia Moretzsohn (2002: 125-127) chamou de "o fetiche da velocidade", expressão que designa as condições de trabalho como fruto de uma dinâmica própria, onde a rotina de produção interfere no resultado final - as notícias.

A alegoria da mcdonaldização, proposta neste trabalho, se baseia nos princípios da homogeneidade e da velocidade aplicados ao processo jornalístico - notadamente o digital -, que resulta em textos estandardizados, pasteurizados, superficiais, sem tempo para aprofundamento, culminando naquilo que denominamos jornalismo binário. O jornalismo binário seria o jornalismo reduzido à sua mínima essência, muitas vezes sem o cuidado de "ouvir o outro lado", com poucas fontes consultadas. São duas as hipóteses: (1) a mcdonaldização seria um fenômeno que incide sobre o jornalismo e afeta as notícias; e (2) o jornalismo binário seria a conseqüência, levando a um produto de menor qualidade. Paralelamente, tecemos o argumento de que a espetacularização seria um recurso que encontra no jornalismo digital (mcdonaldizado) as condições para sua inserção no mundo das notícias on-line - e no mundo real -, configurando-se num epifenômeno, no sentido grego de "movimento para posterioridade" (Cunha, 1986: 306).

Desde que foi fundado por Maurice e Richard McDonald, o McDonald's é símbolo de organização, controle e sucesso empresarial. Batatas fritas cortadas milimetricamente, marcação do tempo de cozimento de hambúrgueres segundo a disposição na chapa, data de validade instantaneamente registrada ao final do preparo do lanche: todas essas variantes, disseminadas de forma idêntica pelas filiais ao redor do mundo, fizeram com que o McDonald's servisse de lastro até para índices que medem a inflação ${ }^{1}$. A referência McDonald's está calcada nos princípios da homogeneidade e da velocidade.

No caso do jornalismo digital - entendido como a atividade jornalística adaptada à rede mundial de computadores -, a teoria da mcdonaldização da sociedade, do sociólogo George Ritzer (2000: 132), traz à tona a questão da pasteurização dos conteúdos. Assim como nas lanchonetes, o sistema de trabalho do jornalista, fator determinante na construção de seu discurso, fica subordinado à lógica da velocidade, como se a cultura de cronômetro fosse inerente à realidade, e não resultado da rotina industrial. As notícias são hoje alinha-
${ }^{1}$ Foi a partir dessa padronização na rotina de montagem que o "burgernomics" criou o índice

Big Mac. Inventada em 1986 como um guia de verificação da estabilidade financeira, a teoria é baseada no princípio da paridade de poder de compra. Em linhas gerais, no longo prazo as taxas de câmbio tenderiam a se igualar, posto que os ingredientes para a fabricação do sanduíche são os mesmos. Isso quer dizer que um dólar, por exemplo, deveria significar poder aquisitivo semelhante em qualquer lugar do planeta. O preço médio de um Big Mac nos Estados Unidos é de U\$ 2,71. Os hambúrgueres mais baratos encontram-se na China, a U\$ 1,20, e os mais caros, na Suiça, a U\$ 4,52, o que significa que o yuan, a moeda chinesa, é a mais desvalorizada de todas, enquanto o franco suiço é a que apresenta maior lastro.

${ }^{2}$ Ritzer é professor da Universidade de Maryland (EUA) e faz estudos sobre consumo, globalização, sendo também um teórico da modernidade e pós-modernidade. Sua teoria da mcdonaldização da sociedade parte do conceito de racionalização de Weber, que o sociólogo norte-americano atualizou. Ele sugere que a cadeia de restaurantes fast-food pode ser vista como um modelo organizacional da sociedade, reduzido às fórmulas de eficiência e controle.

\section{Estudos em Jornalismo e Mídia}


${ }^{3}$ Termo alemão para leitura (leser) furiosa (wut) ou a vontade de ler tudo o que existe. Goethe cunhou o termo em alusão aos leitores que consumiam avidamente toda sorte de impressos.

${ }^{4}$ Um texto preliminar a este, sob o título "Mcdonaldização no jornalismo: o discurso da velocidade", foi apresentado pela autora e por Laryssa Borges no XXVII Congresso Brasileiro de Ciências da Comunicação/ Intercom, em 2004. alinhadas em série, como numa linha de produção digna dos Tempos Modernos, o filme de Charles Chaplin que tão bem ilustra a passagem do homem pré e pós-Revolução Industrial.

Do leitor, configurado pela dromocracia que resulta das facilidades da notícia no último segundo, espera-se um ávido consumidor de informações, integrado no regime da lesewut ${ }^{3}$, onde a dinâmica ágil consolida as hard news e faz do jornalismo digital uma profissão que fornece serviços, não a indivíduos-cidadãos, mas a usuários, consumidores, clientes. $\mathrm{Na}$ verdade, desde a década de 1990 já se conhecia e se disseminava nas empresas jornalísticas brasileiras os conceitos de "turbina informativa" e "informaduto" (Saad, 2003: 91), concebidos como um conjunto de meios de distribuição destinado a transformar notícias em bits, no formato desejado.

Esse conceito da informação - e não mais apenas notícia - como mercadoria caía como uma luva ao setor econômico, a empresários que precisavam de dados da bolsa de valores para tomar decisões, enquanto as produtoras de materiais noticiosos passaram a considerar mais ainda a notícia como "um produto à venda" (Medina,1988: 20). Que poderia, como qualquer outra mercadoria, ser produzido em série e em velocidade para chegar rapidamente ao consumidor; que poderia ser estocado (e gerar um superávit de informação passível de utilização em outros produtos - fascículos, anuários, livros, ou colocados à disposição em outros meios à escolha do leitor); e onde os repórteres seriam os informadutos, produtores ou provedores de conteúdo inseridos na lógica de uma usina de notícias.

Este trabalho trata, portanto, de um fenô- meno que ainda está acontecendo e cujas influências só recentemente começaram a ser sentidas. A mcdonaldização no jornalismo digital brasileiro se manifesta sob a forma da intensificação de fluxos comunicacionais e modificações no processo de produção, provando alterações no produto em si - a notícia -, bem como na cultura profissional. Inserese, pois, entre os temas da teoria construcionista, que estuda as notícias como uma construção social e cultural - onde estão presentes os outros elementos desta ação, o jornalista e sua ideologia -, tendo em vista todo o cenário de transformações que estamos vivendo com o advento dos meios digitais. ${ }^{4}$

\section{Primórdios do McDonald's}

Início da década de 1920 nos Estados Unidos. A ilusão de que andar de carro era mais barato que usar o transporte público - idéia implantada no imaginário popular pelas próprias empresas automobilísticas - fazia crescer a quantidade de carros. É dessa época a construção do primeiro motel do mundo e as primeiras formas do sistema drive-in. Como sugere Schlosser (2001: 33), “os drive-ins encaixavam-se perfeitamente na cultura jovem de Los Angeles. Eram genuinamente novos e diferentes, ofereciam uma mistura de moças, carros e comida fora de hora e, portanto, não demorou para que pipocassem sedutoramente em vários cantos da cidade".

A cem quilômetros do centro da cidade californiana funcionava uma lanchonete de sucesso, que vendia hambúrgueres a 15 centavos de dólar a unidade. Era o McDonald Brothers Burger Bar Drive-In. Maurice e Richard McDonald haviam deixado New Hampshire e migrado para o Sul no início da Grande Depressão, em 1930, na esperança de fugir da falência que havia abatido a fábri- 
ca de sapatos do pai e agarrar a oportunidade óbvia: Hollywood. Trabalharam como cenógrafos nos estúdios da Columbia e, como não conseguiram manter o próprio estúdio de cinema, abriram em 1948 uma lanchonete, tendo como menu: um tipo de hambúrguer e um de cheeseburguer, três sabores de refrigerante, café, leite, batata frita e uma fatia de torta. Como explicaria mais tarde Maurice McDonald, "se déssemos às pessoas uma oportunidade de escolha, seria o caos." O trabalho era feito em etapas: uma pessoa grelhava a carne, outra fritava batatas, a próxima cortava o pão, a quarta fazia milk shakes, e a última ficava no caixa.

Os procedimentos eram detalhados, e as funções, específicas. Os McDonald's conseguiram a rapidez na produção e a economia de trabalho que Henry Ford havia aplicado em sua linha de montagem de automóveis. $\mathrm{O}$ novo sistema, conhecido como Speedee Service, não fez sucesso de imediato. Antes de se tornar o grande nome do ramo alimentício no mundo, o caixeiro-viajante Ray Kroc, vendedor de Multimixers (misturadores para milk shakes), já figurava no rol dos grandes empreendedores americanos, ao lado de John Rockefeller na refinação de petróleo, Henry Ford na montagem de automóveis e Andrew Carnegie na fabricação de aço. Foi Kroc quem implantou definitivamente o conceito de padronização nas lanchonetes McDonald's.

Com o fim da II Guerra Mundial, contratou antigo funcionário dos estúdios MGM para fazer a publicidade. As crianças seriam o público-alvo. O mascote escolhido foi o cozinheiro Speedee, boneco com cabeça de hambúrguer. Logo foi rebatizado para Archie McDonald numa alusão aos já famosos arcos amarelos. Em 1965, foi lançado o novo mascote, Ronald McDonald, que inspirou o jogador Ronaldo a

A tese do
sociólogo
George Ritzer
de que há uma
"mcdonaldização
das sociedades"
encampa a idéia de
que o processo de
transnacionalização
conduz à
uniformização
do globo, a
pequenos mundos
domesticados por
um grande centro
difusor de idéias

Estudos em Jornalismo e Mídia Ano V № 1 - 1o semestre de 2008 homenagear este ícone do consumo, dandolhe o nome de seu primeiro filho, anos mais tarde. As crianças ficavam fascinadas: sanduíches embrulhados como presentes, refrigerantes com canudinhos em formas inusitadas, refeições acompanhadas de brindes. Além de tudo, na recepção havia um palhaço! O Brasil foi o $25^{\circ}$ país do mundo a ter instalada uma lanchonete McDonald's em seu território. Pioneiros na América Latina, os arcos dourados foram fincados em Copacabana, no Rio de Janeiro, em fevereiro de 1979. Logo se espalharam para São Paulo, Curitiba, Belo Horizonte, Salvador e Porto Alegre. A quantidade de restaurantes franqueados cresceu $325 \%$ nos sete primeiros anos.

\section{- Big Mac como símbolo}

No dizer de Featherstone (1987: 22), “o sushi-bar, o ligue-pizza, o delivery chinês ou o Big Mac já não podem ser vistos a partir de seus antigos vínculos orgânicos com as culturas de origem ou Estados-Nação. Passam a fazer parte de uma cultura culinária fastfood, à qual pode-se recorrer com naturalidade, na China, no Uruguai ou nos Estados Unidos. Uma culinária desterritorializada, que transita por um novo (e sobreposto) território, que pode ser designado de global".

A tese do sociólogo George Ritzer de que há uma "mcdonaldização das sociedades" encampa a idéia de que o processo de transnacionalização conduz à uniformização do globo, a pequenos mundos domesticados por um grande centro difusor de idéias. As novas tecnologias esboçariam perfil inusitado: difícil soberania nacional do ponto de vista da cultura e, ao mesmo tempo, inabilidade para o estabelecimento de uma convenção internacional que dê limites à pasteurização. De acordo com Ritzer, a mcdonaldização na eco- 
nomia neoliberal pressupõe: eficiência, calculabilidade, previsibilidade e controle. A padronização da gestualidade para a produção no menor tempo possível retoma os primeiros conceitos de produção de F.W. Taylor, no início do século XX.

O neotaylorismo, no âmbito do fast food, exclui sentimentos e emoções ao padronizar o paladar e induzir à impessoalidade sensorial, aniquila os contextos culturais, ao propor a mesma filosofia de comida rápida, além de servir exatamente a mesma comida com praticamente os mesmos nomes. Trabalha-se ao mesmo ritmo e com a mesma idéia de temporalidade, espacialidade e quantificação. É a previsibilidade e o condicionamento do público para a pressa, o imediatismo, o desejo de saciedade instantânea. O fast food afasta-se da gastronomia e se aproxima da engenharia, distancia-se da diferença e se avizinha da repetição, minimiza o processo para valorizar os resultados.

Hoje, os sanduíches Big Mac, além de serem consumidos fisicamente enquanto substâncias materiais, são consumidos ideologicamente como imagem e ícone do american way of life. São produto de um centro dito superior (ou mais desenvolvido economicamente), que há muito tem sido representado como o centro do mundo. Para os periféricos, oferece-se a possibilidade dos benefícios psicológicos de uma identificação com os poderosos (Featherstone, 1997: 25) e a inserção no processo da economia global. Utilizando as armas da propaganda, os lances espetaculares e os ícones do mundo moderno, o signo McDonald's rapidamente se converteu em uma alegoria para a massificação da cultura e a padronização de um estilo de vida.

Até em Pequim as lanchonetes McDonald's representam tudo o que é americano, junto com a promessa de modernização. Na Alemanha do pós-guerra, por exemplo, o quadro é mais emblemático. O McDonald's Deutschland é a maior empresa alimentícia do país. Existem vários McDonald's espalhados pelas cidades alemãs. Um deles, porém, destoa do contexto em que está inserido. Os sanduíches são os mesmos, as cadeiras são as mesmas, os preços são os mesmos. É um prédio comum, não fosse o fato de ter sido erigido a menos de 500 metros de um campo de concentração. Primeiro campo construído pelos nazistas, o centro de trabalhos forçados de Dachau foi responsável pela morte de 30 mil pessoas. O lucro com os turistas do Holocausto era certo. Houve uma campanha com a distribuição de folhetos e a mensagem: "Bem-vindo a Dachau e bemvindo ao McDonald's" (Schlosser, 2001: 36).

\section{O espetacular na notícia}

Os conceitos de cultura de massas e de indústria cultural (Adorno, 1985) são prérequisito para se compreender os contextos econômicos, sociais e culturais em que surgiu e se desenrola o jornalismo contemporâneo e, mais propriamente, a indústria do jornalismo digital. Hoje, o jornalismo na Web é uma atividade mercantil com características bem definidas, das quais poderíamos apontar: o enxugamento do processo produtivo nas redações - inclusive com o fortalecimento da atuação das agências de notícias -, a produção em série, regras para a construção e apresentação da notícia-mercadoria, num clima de linha de montagem à la Ford (Jorge, 2007).

No jornalismo digital, em tempo real e on-line, todo esse processo atende a três propósitos primários: 1) alcançar o maior número de públicos e camadas sociais; 2) 
proteger os jornalistas de eventuais processos de difamação (Tuchman); e 3) acelerar a finalização das notícias para chegar ao leitor com a ilusão do fato em primeira mão. As agências de notícias são a hegemonização da racionalidade por parte do utilitarismo. $\mathrm{Pa}$ cotes de notícias são despejados pelo mundo na busca de uma uniformidade, a serviço dos atores hegemônicos (Reuters, France Press, Associated Press). Como no McDonald's, o cardápio é reduzido a itens específicos; o pacote de informação pode ser modificado, reduzido, ampliado, ou simplesmente copiado. É no despotismo do dead line que o webjornalismo encarna outra característica da mcdonaldização: a previsibilidade, a pasteurização das notícias ou, como qualifica Ritzer, a mesmice (sameness).

Controlados pelo cronômetro, dedicados à atualidade, obcecados pela novidade, os jornalistas estão continuamente envolvidos numa batalha aparentemente perdida para reagir aos (mais recentes) acontecimentos. (...) A 'invisibilidade' dos processos e das problemáticas exige poder de resposta por parte do campo jornalístico, exige meios para fazer a cobertura de algo não-definido no espaço nem no tempo, exige tempo para elaborar a cobertura. (Traquina, 2001: 90)

Giddens (1991:66) lembra que capitalismo e industrialismo são "feixes organizacionais" das instituições modernas: "Na modernidade, o industrialismo se torna o eixo principal da interação do homem com a natureza." Dois elementos promoveram a aceleração e a expansão das instituições modernas: o desenvolvimento do capitalismo e a globalização. O primeiro se beneficiou do industrialismo, cujo objetivo seria a produção de mais tecnologia,
É no despotismo do dead line que o webjornalismo encarna outra característica da mcdonaldização: a previsibilidade, a pasteurização das notícias ou, como qualifica Ritzer, a mesmice (sameness) por meio de métodos eficientes e baratos; e do uso da força de trabalho abstrato, ponto de conexão entre o capitalismo, o industrialismo e os meios de violência e controle social. Já a globalização caracteriza-se como "intensificação das relações sociais em escala mundial, ligando localidades distantes de tal maneira que acontecimentos locais são modelados por eventos distantes e vice-versa".

A economia capitalista mundial é uma das dimensões da globalização, segundo Giddens. O autor baseia-se em Marx, ressaltando que "o empreendimento capitalista desempenhou um papel importante no afastamento da vida social moderna das instituições do mundo tradicional" e afirmando que, no processo dinâmico do capitalismo, a conexão empresa competitiva/ processo de transformação da mercadoria, por envolver justamente a transformação do trabalho em mercadoria gera o "trabalho abstrato", que pode ser programado no processo tecnológico da produção. A economia capitalista é, segundo Giddens, "instável, inquieta" e, por necessitar de renovação constante, gera um tipo de reprodução que é uma "reprodução expandida".

$\mathrm{Na}$ economia capitalista que tem na informação uma das indústrias, "o jornalismo é um negócio para se produzir um bem de consumo de cuja venda se espera obter lucro", como disse um dos diretores de redação da Folha de S. Paulo, Carlos Eduardo Lins da Silva, lembrando que desse produto, "feito em escala", esperava-se atingir "quantidade de massa" (Ribeiro, 1994: 55, 65-66, 92). Devemos recordar que a idéia da notícia como mercadoria vem do século XIX (Schudson, 1999: 72-73), quando o jornalismo, forçado pela penny press, mudou o status da notícia na nascente sociedade norte-americana, um 
status de mercadoria competitiva no mercado, e de um bem público, coletivo e visível, importante porque, "ao contrário do boato, de pessoa para pessoa, como uma instrução divina", era destinado ao benefício de todos de uma só vez. Num viés mais ideológico, Marcondes Filho afirma:

Notícia é a informação transformada em mercadoria com todos os seus apelos estéticos, emocionais e sensacionais; para isso a informação sofre um tratamento que a adapta às normas mercadológicas de generalização, padronização, simplificação e negação do subjetivismo. Além do mais, ela é um meio de manipulação ideológica de grupos de poder social e uma forma de poder político. (Marcondes Filho, 1986: 13)

Na dialética de Marx, o jornalismo está alicerçado sob três categorias: o singular, o particular e o universal. Para Genro (1989: 14, 191), a trajetória da notícia funciona assim: quando um fato se torna notícia ele é visto pelo ângulo do singular e abre um leque de relações que formam seu contexto particular. No texto jornalístico, o lide atua "como síntese evocativa da singularidade" e realça o particular, destacando pessoas. A notícia decompõe o fato e o reorganiza. No corpo do fenômeno, ela sugere uma universalidade através da significação que estabelece para o singular. Como se o singular fosse universal. É o contexto da singularidade que abre a brecha para a espetacularidade. A notícia - desde os praecor, passando pelos tambores e chegando aos jograis - sempre precisou de chamar a atenção: com gritos, sons, palmas, música. Nesse sentido, transforma-se no meta-acontecimento de Rodrigues (2001: 102-103), "regido pelas regras do mundo simbólico", mais do que pelo mundo natural, e necessita do novo, do inusitado, do exótico e do raro para seduzir.

Mas, como adverte Guy Debord (São Paulo: 1997), “o espetáculo não é um conjunto de imagens, mas uma relação social entre pessoas, mediada por imagens". Embora seja criticado por reduzir a sociedade às relações econômicas, baseando-se e modificando uma afirmativa de Marx, o autor francês quer dizer, segundo Jappe, que "no espetáculo, a economia, de meio que era, transformou-se em fim (...) e a alienação social alcançou o seu ápice: o espetáculo é uma verdadeira religião terrena e material"; que "nunca o poder foi mais perfeito, pois consegue falsificar tudo, desde a cerveja, pensamento, até os próprios revolucionários"; e que "para os donos da sociedade o espetáculo integrado é muito mais conveniente do que os velhos totalitarismos" (Jappe, 1997).

Porém, a definição da contemporaneidade como uma "sociedade do espetáculo", como quer Guy Debord, "é problemática”, segundo Moretzsohn que, com Rubim, apontou que

\section{A notícia - desde os praecor, passando pelos tambores e chegando aos jograis - sempre precisou de chamar a atenção: com gritos, sons, palmas, música}

o espetáculo é inerente a todas as sociedades humanas (dado seu caráter imanente à vida societária, com suas "encenações, ritos, rituais, imaginários, representações, papéis, máscaras sociais, etc.”) e, portanto, está presente “em praticamente todas as instâncias organizativas e práticas sociais, dentre elas o poder político e a política”. (Moretzsohn: 81-84)

Essa seria a primeira ressalva à extensão do conceito de "sociedade do espetáculo". A segunda se refere ao que dissemos antes, e nisso a autora acha que é possível falar em uma sociedade, centrada na mídia, "que tende ao espetacular", já que toda a tecnologia - principalmente a da televisão - predispõe a chamar e disputar a atenção 
das pessoas. Rubim, entretanto, critica a visão apocalíptica de Debord e faz a distinção entre "midiatização" e "espetacularização", onde a adequabilidade dos eventos à mídia exigiria uma linguagem estético-cultural especializada, necessária à veiculação de informações e longe da idéia de um mundo de fatos inserido na lógica do espetáculo.

Destacamos o que Debord fala sobre os meios de comunicação de massa, os quais considera a "manifestação superficial mais esmagadora" do espetáculo, já que parecem invadir a sociedade como simples instrumento de lazer e entretenimento e terminam causando uma ilusão de benefício público. Os meios não são de forma alguma "neutros"; sua comunicação é "unilateral" (da fonte para os consumidores); esses meios participam da movimentação que coloca no ar o espetáculo, e assim se beneficiam dele.

\section{Considerações finais}

O irracionalismo da ânsia pela velocidade, ao considerar esta condição de sobrevivência e de lucratividade para as empresas jornalísticas, abafa o clássico mote de "parem as máquinas" para sugerir o eterno trabalho das rotativas. A máxima "ser interativo ou não ser" (Marc Guillaume) parece perder a importância para "ser veloz ou não ser". Só depois da rápida conexão e do recebimento instantâneo de informações é que se fica verdadeiramente imerso na modernidade. Ser veloz é, por outro lado, assumir a submissão ao ritmo social ditado pela máquina. Os sites noticiosos, munidos da filosofia de que "o público precisa saber", vêem na instantaneidade a questão de que "o público precisa saber mais rápido". Por essa razão, Moretzsohn (2002: 120-122) sugere que a notícia e a velocidade se transformam num fetiche, a
No processo da velocidade reificada, 0 apelo ao exótico

e ao raro pode prevalecer, ajudando a aproximar a notícia do espetáculo que envolve e emociona o público partir do qual o produto do trabalho, tão logo assume a forma de mercadoria, passa a ter 'vida própria', a valer por si, escondendo a relação social que lhe deu origem. É o trabalho abstrato de que falava Giddens, colocado a serviço do industrialismo jornalístico.

A velocidade reificada se evidencia, por exemplo, no slogan da CNN: Slow news, no news (notícias lentas, nenhuma notícia). A emissora instituiu a cobertura 24 horas, o que exige que as notícias sejam atualizadas na menor fração de tempo possível. Na brasileira BandNews, com seu mote "muito mais notícia", as matérias são reprisadas de hora em hora. No caso dos sites, sejam eles ligados a um jornal, revista, rádio ou TV, reproduzem notícias e material de variedades retirados de agências ou de outros veículos do mesmo grupo. Já os portais seriam "um grande guarda-chuva" que junta "outras empresas e agentes jornalísticos e da área de entretenimento" (Saad, 2003: 180). A diretora geral de conteúdo do maior portal brasileiro, o UOL, Márion Strecker, confessa que o espaço do Universo On-Line "não se atém ao jornalismo. Jornalismo é uma parte importante, ao lado de entretenimento e serviços" (Jorge, 2007). Nesse processo, o apelo ao exótico e ao raro pode prevalecer, ajudando a aproximar a notícia do espetáculo que envolve e emociona o público. O portal mantém, por exemplo, uma seção ou estação temática, dedicada às notícias engraçadas ou inusitadas, o UOL Tablóide. Ao estudar as mudanças no radiojornalismo digital, Nélia Del Bianco observou:

Na rede, a proximidade deixa de ser um valor notícia fundamental. Pela natureza global de seu alcance, tudo o que está na rede está próximo de alguém. O complicador dessa situação é que nesse ambiente sem fronteiras podem ga- 
nhar relevância notícias que acentuam valores como exotismo, raridade e insólito de qualquer parte do mundo. Notícias com esses valores sempre tiveram espaço em programas de rádio, porém sempre em doses menores. Ocorre que na Internet esse tipo de conteúdo está em maior volume, o que não deixa de representar um aumento de pressão para sua inclusão nos informativos das emissoras de rádio. (Del Bianco, 2004)

No ciberjornalismo, a qualidade é identificada com a rapidez na transmissão da informação, comprometendo os processos de checagem e apuração. As fontes consultadas costumam ser apenas as regulares, resultando num jornalismo binário, sem aprofundamento, em que apenas um lado das questões é o que prevalece: "O jogo terminou em um a zero"; "a bolsa subiu ou baixou"; "o candidato ganhou ou perdeu o debate". Enquanto no passado o jornalista era o legs'man, o profissional que dependia das próprias pernas para sobreviver, aquele que ia atrás da informação, nas novas modalidades de produção da notícia ele quase não sai da redação, nem se exige isso dele. O risco que corre é o de dar excessivo valor a determinados fatos (o singular) e depreciar outros, que não possuem ingredientes de impacto ou que não tenham capacidade de despertar sentimentos fortes na platéia.

Os jornalistas das redações escrevem cada vez mais sobre fatos que não observaram e sobre assuntos de que não entendem - precisam de bons informantes e intérpretes da realidade; as fontes empresariais e institucionais, geradoras de fatos e atos de relevância social, e detentoras da capacidade de explicá-los, não sobrevivem sem a comunicação com os ambientes externos - precisam dos meios. O problema é que, nesse ajustamento de conveniências, o jornalismo freqüentemente se reduz a algumas técnicas usadas como ferramentas de propaganda, para servir a interesses particulares - às vezes, dos próprios jornais e jornalistas. (Chaparro, 1996)

Voltando a Ritzer, a mcdonaldização no jornalismo junta os pressupostos de eficiência, calculabilidade, previsibilidade e controle, excluindo sentimentos e emoções dos produtores de notícias, ao mesmo tempo em que espetaculariza, provoca artificialmente emoções no público, reduzido a uma mesma dieta sensorial - fast-food e sem opções - onde tudo parece caminhar, pelo menos no jornalismo digital, para uma volta à oralidade.Trabalha-se, nas redações como nas lanchonetes, no mesmo ritmo e com a mesma idéia de temporalidade, espacialidade e quantificação (notícias para a massa), desejando saciar rapidamente o consumidor. Esse fenômeno acaba por ocasionar outros, alguns textuais como a redução no número de temas abordados e dos componentes narrativos, ausência ou enfraquecimento da trama; alguns, de natureza estrutural, como a confusão de gêneros (o chamado info-tainment, por exemplo) e a ênfase no melodrama (Ponte, 2005: 81); e ainda outros, envolvendo as esferas privada e pública, com "espetacularização da primeira e construção de personagens planas na segunda".

Com Debord, vemos que "sob todas as suas formas particulares, informação ou propaganda, publicidade ou consumo direto de divertimentos, o espetáculo constitui o modelo presente da vida socialmente dominante", onde o corolário é dado pelo ato de consumir e as pessoas necessitam identificar-se com algo. O que pode ser o próprio espetáculo (ritmo, temporalidade), o ambiente colorido de uma 
lanchonete com acesso à rede mundial de computadores (espacialidade), ou figuras notórias, sempre tão exploradas pelo jornalismo. Segue-se aí o princípio da cultura das aparências - "o que aparece é bom, o que é bom aparece" - e o da identificação. Este, sem dúvida, um poderoso alavancador de imagens. Os indivíduos, na sociedade do espetáculo, "têm de olhar para outros (estrelas, homens políticos) que vivem em seu lugar" (apud Jappe, 1997).

É nesse aluvião de informações em tempo real que os conteúdos, pedra de toque do jornalismo de prestígio, caem na mesmice. A apuração é medíocre; as fontes, restritas; a reprodução de matérias, uma constante. O fascínio pelas novas tecnologias, que disponibilizam informações cada vez em velocidade mais alta, leva a profissão ao risco de se tornar banalizada, sem função social, inserida a tal ponto no mercado que não há diferença entre consumir uma notícia e um sanduíche, no ambiente espetacular de uma lanchonete. A mcdonaldização do jornalismo é uma tendência em que só o discurso é o da velocidade. A mcdonaldização se nutre de fatos vistos como espetáculo. A espetacularização tem no jornalismo, digital e mcdonaldizado, um lócus perfeito para a integração ao mundo das notícias, e daí funcionar como um epifenômeno do mundo real.

$\mathrm{Na}$ realidade, sob a desculpa da racionalidade, ocultam-se as maneiras como são obtidas as notícias, as condições de trabalho desumanas dos jornalistas e a concorrência às vezes desleal e sempre frenética em busca de dar a notícia primeiro. Assim, as redações digitais arriscam-se a se tornar meros centros de informação pasteurizada, burocratizada, espetacularizada, onde os jornalistas praticam a "reprodução expandida" de Giddens, tudo, porém, sob controle. Os jornalistas, entrincheirados em seus computadores, copian- do conteúdos de agências de notícias, reiteram a hipótese de que o jornalismo, em especial o digital, seja apenas um dos elementos que compõem o marketing-mix da comunicação, dando preferência àquilo que se convencionou chamar, nos cadernos ditos de cultura dos periódicos e nas páginas de entretenimento dos sites, artes e espetáculos.

\section{Sobre a autora}

Thaís de Mendonça Jorge, Doutora em Comunicação pela UnB, docente da Faculdade de Comunicação.

email: thaisdemendonca@uol.com.br

\section{Referências}

ADORNO, Theodor \& HORKHEIMER, Max. Dialética do Esclarecimento. Rio de Janeiro: Jorge Zahar, 1985.

CHAPARRO, Manuel. Jornalismo na fonte. Seminário de comunicação. Brasília: Banco do Brasil, 1996.

CUNHA, Antônio G. Dicionário etimológico Nova Fronteira da Língua Portuguesa. Rio de Janeiro: Nova Fronteira, 1986: 306.

DEL BIANCO, Nélia R. Radiojornalismo em mutação. A influência tecnológica e cultural da Internet na transformação da noticiabilidade no rádio. Tese (Doutorado em Comunicação) - Universidade de São Paulo, Escola de Comunicações e Artes, São Paulo, 2004.

FEATHERSTONE, Mike. O desmanche da Cultura. São Paulo: Sesc/Studio Nobel, 1997.

GENRO FILHO, Adelmo. O segredo da pirâmide. Para uma teoria marxista do jornalismo. Porto Alegre: Ortiz, 1989.

GIDDENS, Anthony. As conseqüências da modernidade. São Paulo: Unesp, 1991.

JAPPE, Anselm. São Paulo, Folha de São Paulo, suplemento Mais!, p. 5, 17 ago. 1997.

\section{Estudos em Jornalismo e Mídia}


JORGE, Thaïs de M. A notícia em mutação. Estudo sobre o relato noticioso no jornalismo digital. Tese (Doutorado em Comunicação) - Universidade de Brasília, Faculdade de Comunicação, Brasília, 2007.

MARCONDES FILHO, Ciro. O capital da notícia. Jornalismo como produção social da segunda natureza. São Paulo: Ática, 1986.

MEDINA, Cremilda. Notícia, um produto à venda: jornalismo na sociedade urbana e industrial. São Paulo: Summus, 1988.

MORETZSOHN, Sylvia. Jornalismo em "tempo real": o fetiche da velocidade. Rio de Janeiro: Revan, 2002.

Pensando contra os fatos. Jornalismo e cotidiano: do senso comum ao senso crítico. Rio de Janeiro: Revan, 2007.

PONTE, Cristina. Para entender as notícias. Linhas de análise do discurso jornalístico. Florianópolis: Insular, 2005.

RITZER, George. The McDonaldization of Society. Thousand Oaks: New Century, 2000.

RODRIGUES, Adriano. D. Estratégias da Comunicação. Questão comunicacional e formas de sociabilidade. Lisboa: Presença, 2001.

RIBEIRO, Jorge C. Sempre alerta. Condições e contradições do trabalho jornalístico. São Paulo: Olho dágua/ Brasiliense, 1994.

SAAD, Beth. Estratégias para a mídia digital: Internet, informação e comunicação. São Paulo: Editora Senac, 2003

SCHLOSSER, Eric. País Fast Food. São Paulo: Ática, 2001.

SCHUDSON, Michael. The Power of News. Cambridge/ Londres: Harvard University Press, 1999. TENGARRINHA, José M. História da Imprensa Periódica Portuguesa. Lisboa: Caminho, 1986. TRAQUINA, Nelson. O estudo do jornalismo no século XX. São Leopoldo: Unisinos, 2001.

\section{Referências Webgráficas}

DEBORD, Guy. A sociedade do espetáculo. In: http://www.terravista.pt/IlhadoMel/1540/ Acesso em: 1 mar. 2008.

Recebido em 3 de março de 2008 Aprovado em 28 de abril de 2008 